Mapping synergies and trade-offs between urban ecosystems and the

\title{
Sustainable Development Goals
}

Mikaël J. A. Maes ${ }^{1,2,4^{*}}$, Kate E. Jones ${ }^{2,3}$, Mireille B. Toledano ${ }^{4}$, and Ben Milligan ${ }^{{ }^{*}}$

${ }^{1}$ Department of Geography, University College London, Pearson Building, Gower Street, London, WC1E 6BT, United Kingdom.

${ }^{2}$ Centre for Biodiversity and Environment Research, Department of Genetics, Evolution and Environment, University College London, Gower Street, London, WC1E 6BT, United Kingdom.

${ }^{3}$ Institute of Zoology, Zoological Society of London, Regent's Park, London, NW1 4RY, United Kingdom.

${ }^{4}$ MRC-PHE Centre for Environment and Health, School of Public Health, Faculty of Medicine, Imperial College London, Norfolk Place, London W2 1PG, United Kingdom

${ }^{5}$ Centre for Law and Environment, University College London, Bentham House, Endsleigh Gardens, London WC1H 0EG, United Kingdom

* Corresponding authors: mikael.maes.16@ucl.ac.uk and b.milligan@ucl.ac.uk (Tel: +44

(0)20 31087691)

Word Count (Items): Total - 6542 (Abstract - 268; Main Text - 4530; References - 1744). 
Urban ecosystems and the Sustainable Development Goals - Maes et al. (2018)

\begin{abstract}
Global urbanisation has increased pressures on ecosystems located within city boundaries, resulting in loss and fragmentation of urban ecosystems. In September 2015, the United Nations adopted the 2030 Agenda for Sustainable Development which includes 17 Sustainable Development Goals (SDGs) and 169 SDG targets. It made environmental sustainability a key component of the agenda, whose preamble recognises that social and economic development depends on the sustainable management of Earth's natural resources. Understanding the interlinkages between the broad and globally focused 2030 Agenda and components of the natural environment remain a practical challenge for both researchers and decision-makers in all disciplines. It is unclear how SDG targets relate to urban ecosystems and what evidence base supports these relationships. Here, we address what changes are required concerning urban ecosystem management and how management of urban ecosystems can reinforce or undermine action to deliver all 169 targets in the 2030 Agenda. We characterised 91 targets requiring action in relation to urban ecosystem management. These collectively emphasise the need to sustainably manage nature, provide equal rights to basic services, pursue sustainable economic growth, and strengthen governance and policy development at multiple scales. We identified 102 targets (99 synergies and 51 trade-offs) with published evidence of relationships with urban ecosystems, where decisions about urban ecosystems affect humanities ability to realise greater welfare and well-being, and build physical and social infrastructure. These findings highlight that sustainable management of urban ecosystems cannot be achieved without addressing other issues such as economic growth, equality or good governance. Translating these interlinkages into a strategy supported by all actors in society is important for achieving sustainable urban ecosystem management.
\end{abstract}

Keywords: urban ecosystems, green infrastructure, sustainable development goals, naturebased solutions, cities 


\section{GRAPHICAL ABSTRACT}

\section{Problem}

It is unclear how SDG targets relate to urban ecosystems and what evidence base supports these relationships

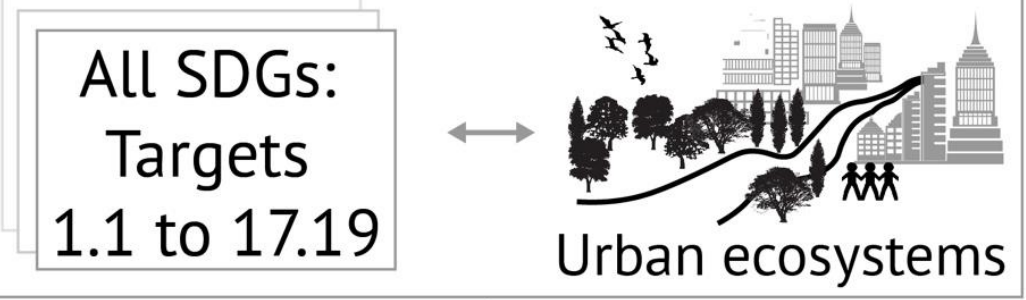

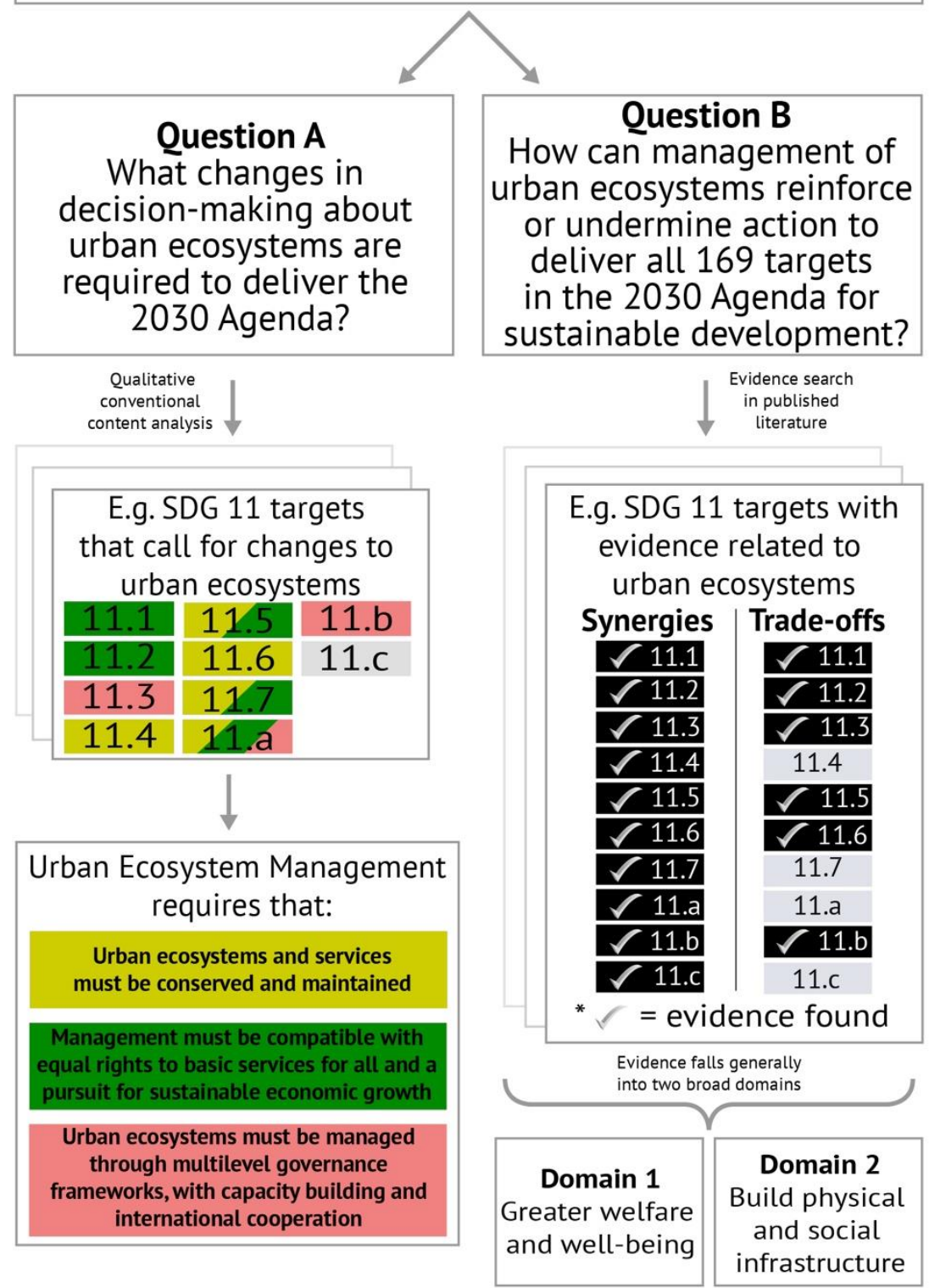


Urban ecosystems and the Sustainable Development Goals - Maes et al. (2018)

\section{INTRODUCTION}

Cities are centres for innovation, culture, commerce and science. The possibilities within cities to pursue better social and economic opportunities has been a key driver for global urbanization trends (UN HABITAT, 2016). More than half of the world's population ( 54\%) now lives in urban areas (UN HABITAT, 2016). This share could increase to $\sim 66 \%$ of the global population by 2050 (UN, 2015a). Urbanisation has increased pressures on ecosystems, especially those that lie within city boundaries. This has resulted in shrinking green spaces, habitat fragmentation, pollution or contamination of natural environments (Fengxiang et al., 2003; Fischer and Lindenmayer, 2007; Hermansen et al., 2017; Hung et al., 2017) and decline of biodiversity (CBD, 2010). The impact of urban lifestyles and the built environment on urban ecosystems and their ecological processes is now regarded as a key impediment to the sustainable development of cities (Forman, 2014; Francis and Chadwick, 2013; Gaston, 2010).

An increasing body of evidence shows that components of urban ecosystems can help manage cities through improvements in water retention and purification (Forman, 2014), mitigation of the urban heat island effect (Akbari et al., 1997; Vaz Monteiro et al., 2016), the creation of biodiversity hotspots (Farinha-Marques et al., 2011) and benefits for human health and well-being (Hartig et al., 2014). Associations between urban ecosystems and human health and well-being are not well understood and mostly based on correlative studies, i.e. simple relationships between a number of variables without necessarily understanding the causal relationship behind it. An increase of urban ecosystems has been associated with improvements of local air quality (Gauderman et al., 2015; Kardan et al., 2015; Landrigan et al., 2017; Nowak et al., 2014), increases in physical activity (Coombes et al., 2010; Richardson et al., 2013), improvements in mental health (Duarte Tagles and Idrovo, 2012; MacKerron and Mourato, 2013) and a decrease of stress levels (Roe et al., 2013; Thompson et al., 2012).

Growing political concern about the implications of ecosystem loss-both within and beyond cities - for social and economic development has prompted ambitious commitments being made at a global level. The 2000 Millenium Summit launched 8 Millenium Development Goals (MDGs) for the year 2015. Although successes were made (UN, 2015b), there was a need for a new global agenda on sustainable development. In September 2015, the 193 members of the United Nations (UN) General Assembly formally adopted the UN 
Urban ecosystems and the Sustainable Development Goals - Maes et al. (2018)

Sustainable Development Goals (SDGs). The preamble of the 2030 Agenda recognises the importance of sustainably managing Earth's natural resources as an important basis for present and future social and economic development. The 2030 Agenda features 17 SDGs and 169 targets that set out global objectives for sustainable development on matters such as climate change, economic growth, poverty eradication and urban development (UN, 2015c). Translating the broad and globally focused 2030 Agenda into a specfic decision-making context is an important practical challenge for decision-makers in all sectors (ICSU, 2017). Here, we respond to a subset of this broad challenge by addressing two questions focused on urban ecosystems and their management; (A) What changes in decision-making about urban ecosystems are required to deliver the 2030 Agenda? (B) On the basis of current evidence, how can management of urban ecosystems - in particular investment, conservation, and enhancement of those ecosystems - reinforce or undermine action to deliver all 169 targets in the 2030 Agenda for sustainable development? Previous analyses have attempted to map environment-human interactions for all SDGs and synthesised relevant evidence and knowledge gaps between each SDG and the environment (Scharlemann et al., 2016).Our analysis builds on this by focusing specifically on only one element of the natural environment (i.e. urban ecosystems) and by giving a more detailed analysis of its implications for future sustainable management.

\section{METHODS}

\subsection{NORMATIVE IMPLICATIONS OF THE 2030 AGENDA FOR MANAGEMENT OF URBAN ECOSYSTEMS}

Identification of principles for sustainable development of urban ecosystems entails analysis of the content of the SDGs in order to identify all SDG targets that stipulate action in relation to urban ecosystems. We assessed the normative implications of all 169 targets for their interlinkages with urban ecosystems by answering the following question: Does this SDG target call for action in relation to urban ecosystems (Figure 1A)? For example, SDG target 1.4 calls for 'all men and women to have equal rights to economic resources' including natural resources extracted from urban ecosystems. Based on the language from the Convention on Biological Diversity (CBO, 2012), we defined 'urban ecosystems' broadly as all functioning ecosystems that hold a variety and richness of living organisms in cities, including coastal and estuarine ecosystems which are spatially adjacent to or surrounded by 
Urban ecosystems and the Sustainable Development Goals - Maes et al. (2018)

the built urban environment. After identifying all SDG targets that call for action in relation to urban ecosystems, these targets were then distilled into a list of core principles for sustainable development of urban ecosystems. A consensus-based qualitative content analysis was undertaken to identif key cross-cutting normative themes concerning the management of urban ecosystems. The qualitative content analysis contained three stages: (1) the wording of all identified SDG targets was individually summarised into a maximum set of three themes which can be either a word or a short sentence, (2) the themes in stage one were once again summarised into a maximum set of three themes for each SDG which again can be either a word or a short sentence, and (3) a final three key themes were identified for all SDGs together based on the themes of stage two. Results and their implications for urban decisionmakers are discussed in section 3. This analysis was informed by Elo and Kyngäs (2008) and enables us to iteratively summarise the normative content of the SDG targets in a transparent and reproducible way (Harwood and Garry, 2003). This systematic procedure avoids imposing our own value judgement and minimises subjectivity in the analysis of the normative content.

\subsection{SYNERGIES AND TRADE-OFFS BETWEEN URBAN ECOSYSTEM MANAGEMENT AND SUSTAINABLE DEVELOPMENT}

To understand how management of urban ecosystems can reinforce or undermine action to deliver all 169 targets in the 2030 Agenda, we identified evidence of empirical relationships (synergies or trade-offs) between action to deliver one target and actions to invest in, conserve and enhance urban ecosystems (Figure 1B). We used a consensus-based approach to identify synergies and trade-offs, which involved the search for published studies in peerreviewed journals and reports published by non-academic organisations (e.g. UN reports) using the Google Scholar search engine. These results were refined through facilitated discussions by all experts until a consensus was reached. The experts (the authors of this paper) consisted of academics from diverse disciplines spanning medicine, natural sciences and law. As we do not seek to make a definitive statement on the relationship between urban ecosystems and the SDGs, a single item of published evidence was considered sufficient to indicate the presence, if any, of a synergy or trade-off between the SDG target and urban ecosystems, which otherwise would require a larger systematic literature review. We considered the presense or absence of the interaction only (i.e. whether it is a synergy or trade-off). Weighting the interaction as suggested by Nilsson et al. (2016) is not done here 
because estimating whether an SDG target is, for example, inextricably linked to the achievement of another goal, or whether it aids the achievement of another goal can be arbitrary. It is also fundamentally impacted by geography, governance and technology (Nilsson et al., 2016).
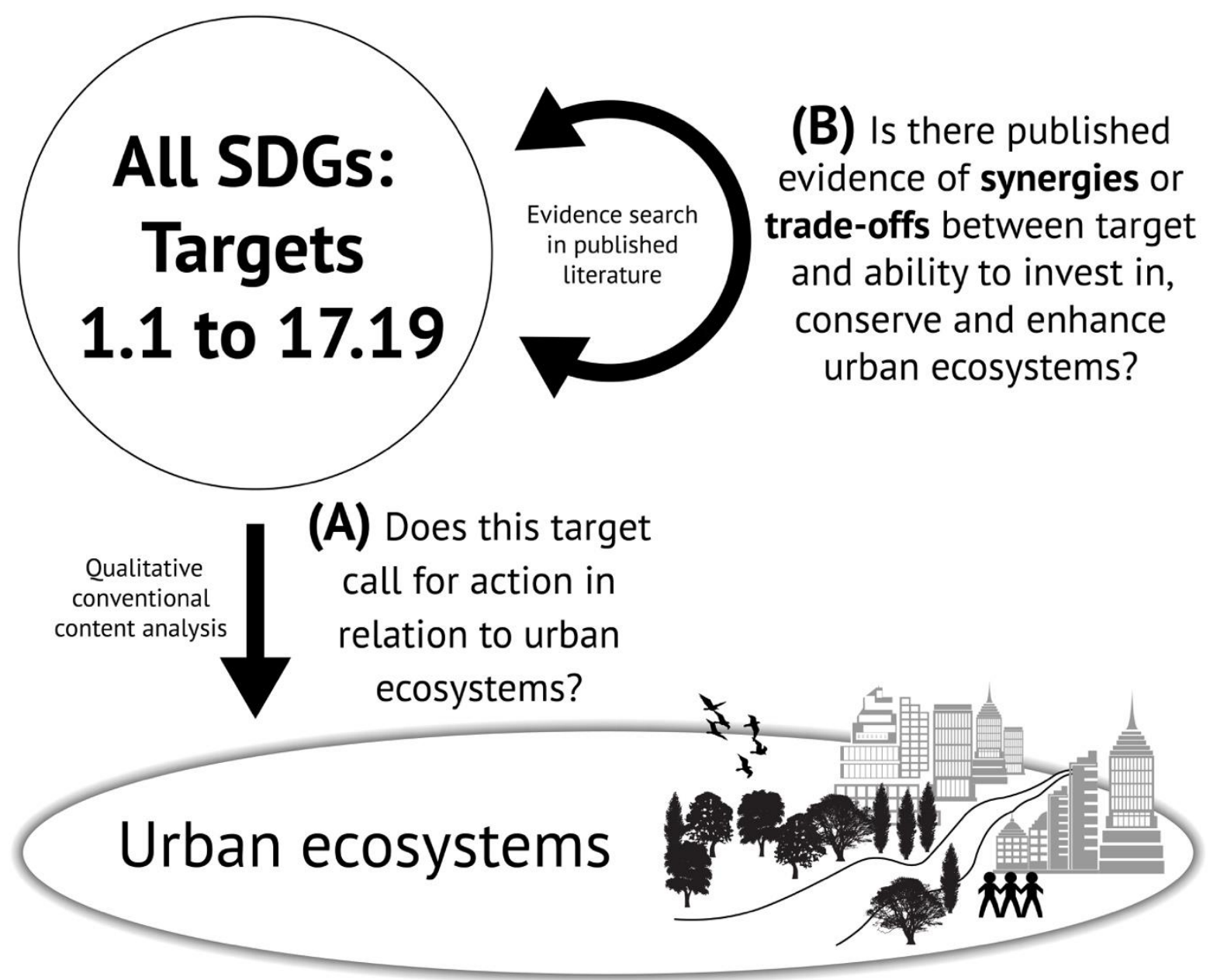

Figure 1. Assessing interlinkages between the SDG targets and urban ecosystems. An illustration of the research questions and methods used for assessing each SDG target in relation to urban ecosystems. (A) What changes in decision-making about urban ecosystems are required to deliver the 2030 Agenda? (B) How can management of urban ecosystems reinforce or undermine action to deliver all 169 targets in the 2030 Agenda for sustainable development?

\section{NORMATIVE IMPLICATIONS OF THE 2030 AGENDA FOR MANAGEMENT OF URBAN ECOSYSTEMS}

We found that 91 targets (54\%) call for action in relation to urban ecosystems (Figure 2A). This includes a variety of actions such as protecting ecosystems (e.g. targets 14.2, 15.1, 15.5 and 15.7), providing equal rights to different types of services (e.g. targets 2.1, 7.1 and 11.1) and improving governance and cooperation (e.g. targets 13.3, 16.6, 16.7 and 17.9). The 
Urban ecosystems and the Sustainable Development Goals - Maes et al. (2018)

qualitative content analysis summarises the diverse range of actions for each SDG (Figure

2B) into three key themes to sustainably manage urban ecosystems by 2030 (Figure 2C), i.e.

(1) urban ecosystems must be conserved and maintained, (2) management must be compatible with equal rights to basic services for all and a pursuit of sustainable economic growth and (3) urban ecosystems must be managed through multilevel governance frameworks, with capacity building and international cooperation. These key themes give a strong indication of the substantial change needed in other disciplines in pursuit of sustainably managing urban ecosystems. Our results are documented in full in the electronic supplementary material. 


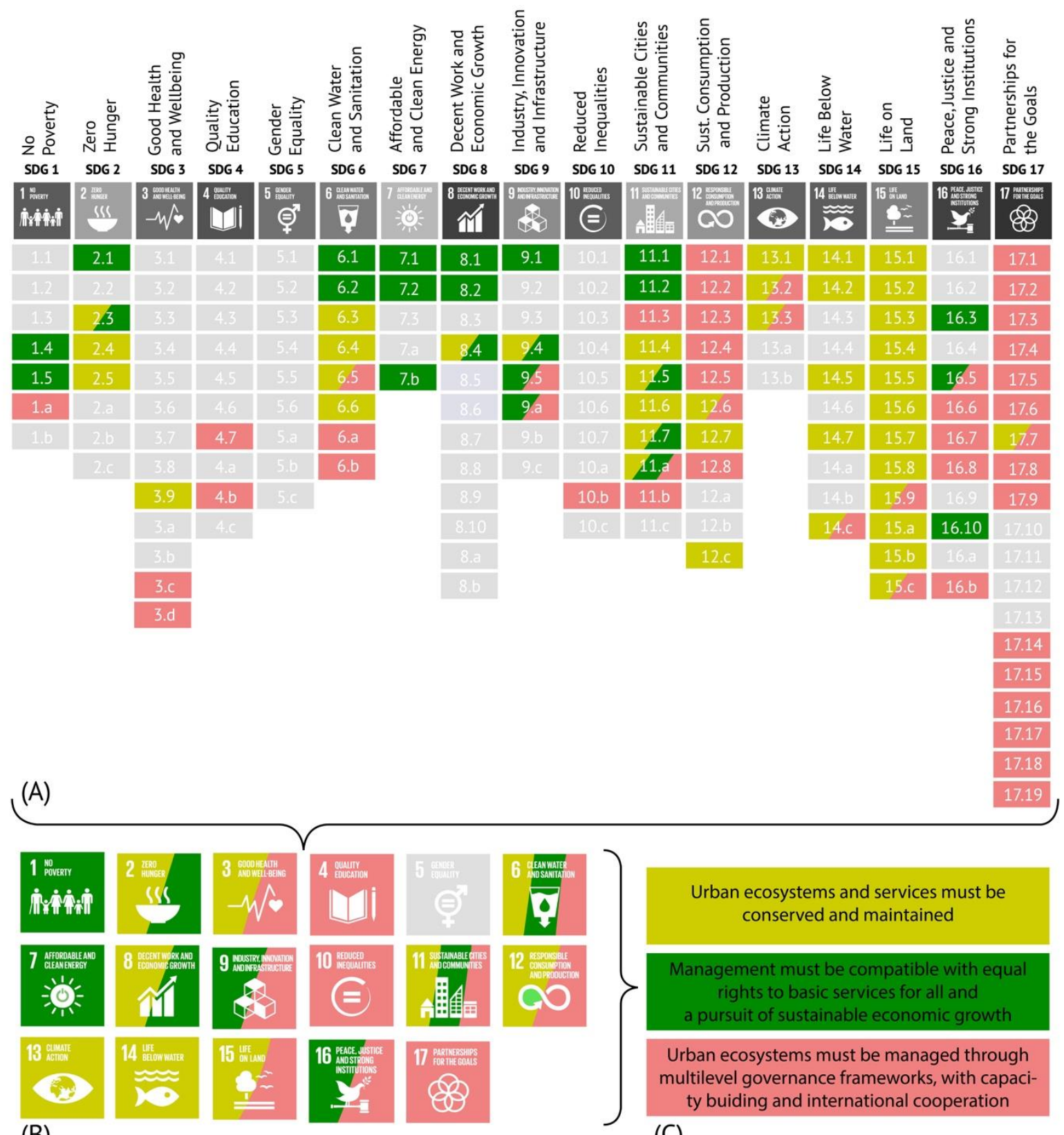

(B)

(C)

Figure 2. Identifying key themes to sustainably manage urban ecosystems. This figure shows a graphical illustration of the qualitative content analysis undertaken on all SDG targets that call for actions in relation to urban ecosystems. Yellow, green and red are used to highlight the key themes identified throughout the qualitative content analysis. A mixture of more than one colour indicates that more than one key theme is identified in (A) identified targets, (B) identified SDGs and (C) resulting key themes that call for actions in relation to urban ecosystems. Full results of the assessment for each target can be found in the electronic supplementary material. 


\section{SYNERGIES AND TRADEOFFS BETWEEN URBAN ECOSYSTEM MANAGEMENT AND SUSTAINABLE DEVELOPMENT}

We identified evidence of synergies and trade-offs between 102 targets (60\%) out of 169 targets and actions to invest in, conserve or enhance urban ecosystems. These synergies and trade-offs span all 17 SDGs and cover many different topics relevant to the subject matter of the 2030 Agenda targets such as poverty eradication, economic growth, physical infrastructure and environmental protection. 99 targets (59\%) out of 169 targets were identified to have synergies (Figure 3A), while only 51 targets (30\%) were identified to have trade-offs in relation to decisions about urban ecosystems (Figure 3B). 48 targets out of 102 identified targets have evidence for both synergies and trade-offs within the target, suggesting these SDG targets can both reinforce and undermine action to invest in, conserve or enhance urban ecosystems. This evidence of synergies and trade-offs falls generally into two domains, where decision-making about urban ecosystems affects our ability to (1) realise greater welfare and well-being, and (2) build physical and social infrastructure. Identified evidence within each of these domains is discussed in more detail below. 
Urban ecosystems and the Sustainable Development Goals - Maes et al. (2018)

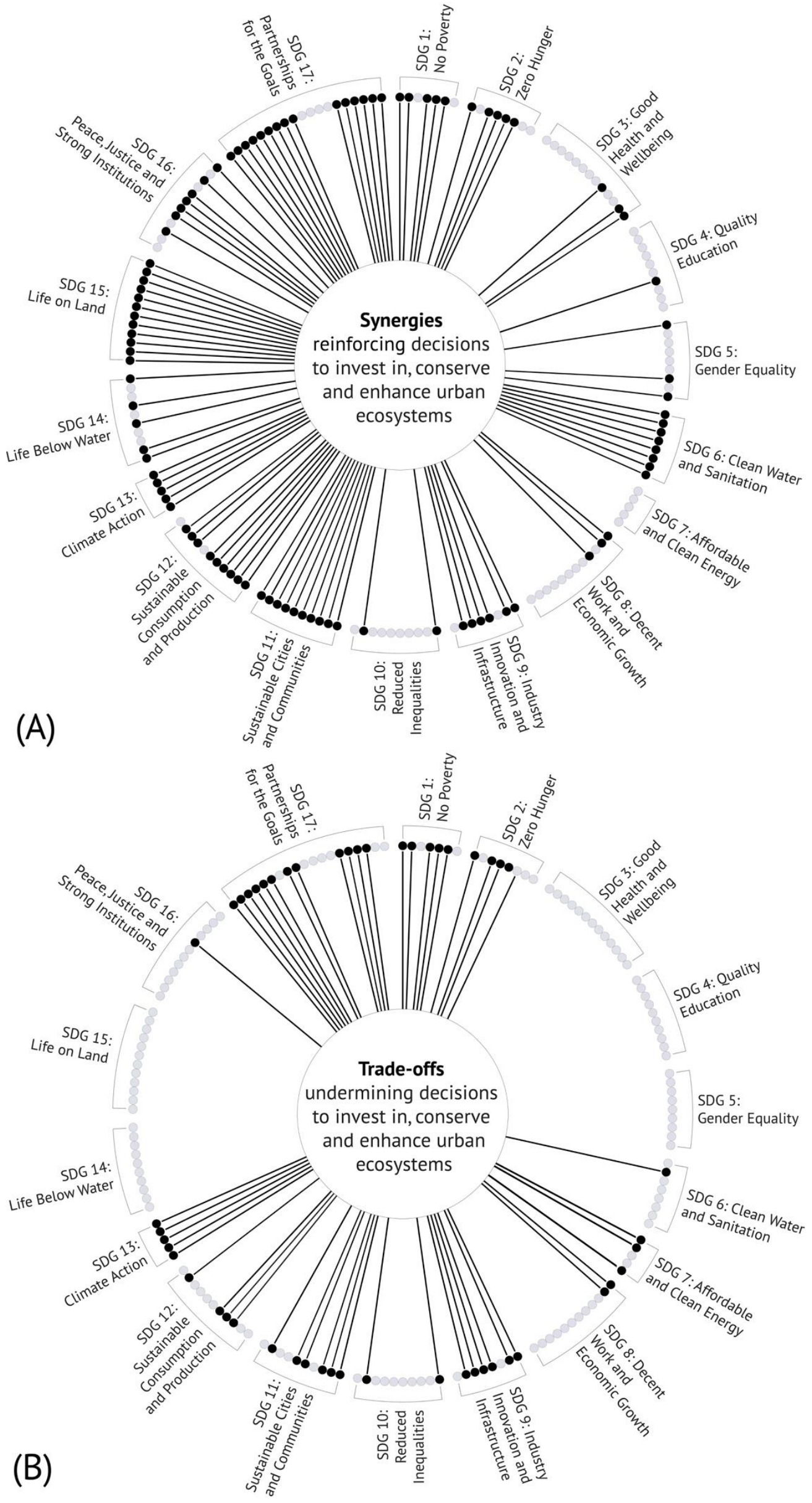


Figure 3. Synergies (A) and trade-offs (B) between urban ecosystems and SDG targets. Targets are ordered clockwise; for example, target 1.1 is represented by the leftmost circle in the group associated with SDG 1 . Targets highlighted in black indicate that published evidence was identified in relation to decisions about urban ecosystems for synergies, or trade-offs. Whereas targets highlighted in grey indicate the absence of identified published evidence. This does not indicate the absence of synergies or trade-offs between that target and decisions about urban ecosystems. Full results of the assessment for each target can be found in the electronic supplementary material.

\subsubsection{Greater welfare and well-being}

The availability of well-managed, high-quality urban ecosystems is important for greater welfare and well-being. The role of urban ecosystems to this domain is illustrated by 57 targets involving synergies with the ability to invest in, conserve and enhance urban ecosystems. For example, peaceful, transparent and accountable institutions (SDG 16) are important for realising greater welfare and well-being. Changes need to be made in governance of urban ecosystems, strengthening the rule of law, reducing corruption, increasing participation at all levels and providing access to information (i.e. SDG targets 16.3, 16.5, 16.6, 16.7 and 16.10) (UNEP, 2012). Our analysis also showed synergies between gender and environment (i.e. SDG target 5.1, 5.a and 5.c). Narrowing gender gaps in agriculture, water and sanitation and other areas has been identified to increase society's productivity (UNEP, 2016). Synergies for good health and well-being are underrepresented in the domain of greater welfare and well-being. Only 3 out of 13 targets from SDG 3 were identified to have synergies (i.e. SDG targets 3.9, 3.c and 3.d). Urban ecosystems however, are considered a key-ecosystem based approach offering sustainable and cost-efficient solutions to particular health challenges by increasing physical activity (Hartig et al., 2014; McMorris et al., 2015) and reducing particular air pollutants as discussed in SDG target 3.9 (Nyberg et al., 2000; Tallis et al., 2011; Yang et al., 2008). Bowen and Lynch (2017) reviewed the potential for green infrastructure as an ecosystem-based climate adaptation tool for cities and indicated that there is still considerable debate on the human health benefits of urban ecosystems. Therefore, the evidence base of health and well-being benefits from urban ecosystems is limited, and many SDG 3 targets have no published evidence of synergies that relate to subjects known to be connected to issues of the environment (e.g. reducing maternal mortality, ending the epidemics of AIDS or halving deaths related to road traffic accidents). Together, these explain why our analysis only found limited representation of synergistic responses between good health and well-being and this domain. 
Urban ecosystems and the Sustainable Development Goals - Maes et al. (2018)

Aspirations for greater welfare and well-being also has 23 targets involving trade-offs with the with the ability to invest in, conserve and enhance urban ecosystems. For example, eradicating poverty plays a fundamental role in conserving urban ecosystems. Poverty is known to increase pressure on land-use and hinder the conservation of natural ecosystems, especially in cities (Alix-Garcia et al., 2015; Duraiappah, 1998). Raising living standards however, through the provision of basic services such as access to sanitation facilities, energy, and housing services (i.e. SDG target 6.2, 7.1 and 11.1), can change environmental pressures from land-use pressures to increases in pollution (Duraiappah, 1998; Richards et al., 2017; Stern et al., 1996). Therefore, the interlinkages between poverty and urban ecosystems are complex and can have synergies and trade-offs in either direction.

\subsubsection{Physical and social infrastructure}

Building physical and social infrastructure connects with aspirations to realise greater welfare and well-being. Both are underpinned by the natural environment, including urban ecosystems (Waage et al., 2015), highlighting the connectedness between the identified domains and our evidence search in published literature. There is published evidence of 82 targets with synergies between urban ecosystems and actions related to building physical and social infrastructure. For example, Shafik (1994) discussed how access to sanitation and hygiene can reduce environmental pollution, including pollution that would otherwise affect urban ecosystems. Providing access to sanitation and hygiene can therefore be synergetic with the ability to invest in, conserve or enhance urban ecosystems (i.e. SDG target 6.2). Providing access to green and public spaces (i.e. SDG target 11.7) has synergies by creating new green spaces, while reducing social inequalities (Wolch et al., 2014). Other identified evidence showed synergies between waste management and the ability to invest in, conserve or enhance urban ecosystems. For example, Zhao et al. (2011) showed that adequate separation of food waste can result in a more environmentally friendly waste management system. We found no published evidence of synergies for SDG 7 targets (i.e. affordable and clean energy). The absence of identified synergies between SDG 7 and this domain does not imply absence of such evidence for natural ecosystems generally, as there can be synergies that were either not identified in our analysis or are currently understudied.

Evidence of 40 trade-offs were identified between urban ecosystems and building physical and social infrastructure. For example, Sokka et al. (2016) studied the environmental impact of renewable energy targets in Finland and found several environmental impacts of future 
Urban ecosystems and the Sustainable Development Goals - Maes et al. (2018)

renewable energy use, even though these environmental impacts are considered to be low. Other identified evidence showed trade-offs between access to affordable housing and the ability to invest in, conserve or enhance urban ecosystems (i.e. SDG target 11.1). For example, Pauleit et al. (2005) showed that urban densification resulted in a loss of green spaces to large extent because of an increase in buildings, including housing development amongst others. Most identified trade-offs are related to land-use changes as expanding physical and social infrastructure can increase pressure on land currently occupied by urban ecosystems such as climate adaptation measures (Fezzi et al., 2015) and energy infrastructure (Hernandez et al., 2014; Sokka et al., 2016). In fact, access to sanitation and hygiene as discussed above can also affect urban ecosystems because of land-use pressures. Many of the targets with identified trade-offs in this domain have an accompanied synergy for that same target. Therefore, a key aspect of this domain is how the natural environment, which includes urban ecosystems, is taken into consideration when building physical and social infrastructure.

\section{IMPLICATIONS FOR URBAN ECOSYSTEM SCIENCE AND}

\section{POLICY}

Our analysis maps the relationships between urban ecosystems and broader development goals of the 2030 Agenda, building on growing political awareness and previous research that many themes are well connected among one another (Le Blanc, 2015; Waage et al., 2015). We revealed that sustainable management of urban ecosystems cannot be achieved in isolation from other issues such as economic growth, equality or good governance. Our result is a first attempt to expose the complex relationships between urban ecosystems and the SDGs. It shows that sustainable management of urban ecosystems cannot be achieved without acknowledging the role of human wellbeing, and physical and social infrastructure. We showed that almost all SDGs and 54\% of targets call for action in relation to urban ecosystems. This analysis also exposed the need for government structures that account for synergies and trade-offs to incorporate these results in policy decision-making. Organising evidence of synergies and trade-offs can help policymakers and researchers identify pathways that minimise negative interactions and enhance positive ones. We found evidence of synergies between 99 targets and decisions related to urban ecosystems, indicating that 59\% of targets are mutually reinforcing of sustainable management of urban ecosystems. We also found evidence of trade-offs between $30 \%$ of targets and decisions relating to urban 
Urban ecosystems and the Sustainable Development Goals - Maes et al. (2018)

ecosystems. Most evidence of trade-offs identified in this analysis are related to land-use changes.

Our analysis does not identify which synergies or trade-offs are most important in relation to urban ecosystems. Future context-specific analyses of synergies and trade-offs may wish to weight these relative to each other to support planning and decision-making, recognising of course that weighting of these factors is not solely an objective process (Nilsson et al., 2016). Rather, our analysis is intended to serve as a basis to start a discussion on the integration of other disciplines such as poverty eradication or good governance, which until now have not been traditionally on the agenda for actors involved in the sustainable management of urban ecosystems. Achieving the SDGs is a long and difficult exercise and requires action from all actors in society.

\subsection{IMPLICATIONS FOR THE RESEARCH COMMUNITY}

Academic institutions need to extend outside classic academic fields to understand how different disciplines interact with each other. As we have illustrated here, action to manage urban ecosystems is influenced by more than just conservation issues and is interacting with issues such as poverty, governance, economic growth, and health. Encouraging interdisciplinary work related to urban ecosystems requires actors to share data and knowledge with others outside their own academic fields and set up interdisciplinary collaborations. Academic understanding of urban green infrastructure and its interrelationships with microclimate, nutrient and water household, and human health, amongst others, is insufficient in many disciplines. For example, several studies using dose-response relationships have identified positive associations between green infrastructure and human health (Cox et al., 2017a, 2017b; Shanahan et al., 2016). Whilst there is a broad consensus that green infrastructure provides particular physical and mental health benefits (Coutts and Hahn, 2015; Hartig et al., 2014), there is very limited understanding of how these health benefits are delivered and what mechanisms are responsible to deliver these health benefits. Franco et al. (2017) suggest that specific research is needed focusing on (i) non-visual pathways for delivering health benefits of green infrastructure, and (ii) stronger interdisciplinary work that goes beyond correlational studies to identify causal relationships.

There is no comprehensive understanding of how to incorporate interdisciplinary collaboration related to urban ecosystems into policy structures and deploy it in specific cities or decision contexts. More recently, focus is shifting from ecosystem-based approaches to 
Urban ecosystems and the Sustainable Development Goals - Maes et al. (2018)

nature-based solutions (NBS), broadly defined by Raymond et al. (2017) as solutions to societal challenges that are inspired and supported by nature. NBS provide social and economic benefits and costs, and the value of these additional benefits is not well assessed in current decision-making structures (Raymond et al., 2017). Since city governments highly value decisions based on budget impacts and return on investments (Bowen and Lynch, 2017), an approach that includes social and economic benefits and the costs such as NBS, could provide opportunities in specific decision-making contexts (Maes and Jacobs, 2017). This suboptimal understanding of urban green infrastructure is strengthened by the conventional academic silos in which they are operating. To enhance our understanding of the impact of urban green infrastructure, we need to break down academic silos, connect different disciplines and actors, and increase the body of research that focuses on a mechanistic understanding of urban green infrastructure in relation to humans and society. This can be done for example by linking urban green infrastructure research with specific targets and goals, as we have illustrated here.

\subsection{IMPLICATIONS FOR POLICY-MAKING}

The SDGs have emphasised that effective protection of urban ecosystems is only possible by addressing other societal challenges such as poverty eradication, sustainable economic growth, and transparent and accountable institutions on all levels. Understanding the interactions between these different disciplines is complex because of the many synergies and trade-offs between targets and SDGs, as we have shown here. Decision makers in the public and private sector need to break down barriers between different sectors and departments, and enable more integrated policies that account for interdependencies across SDG themes (Le Blanc, 2015). In practice, this implies decision makers need to transform the decision-making process and mainstream environmental considerations into local, national and global urban policy-making. As a response to the growing demand from local, regional and national governments for assistance in sustainable urban policy-making and planning, new bodies were developed by the UN Environment Programme and the UN Human Settlement Programme such as the Green Cities Partnership and the Urban Planning and Design Lab, which support through technical expertise and financial contributions. For example, the city of Chengdu received international support through the Green Cities Partnership to advance the development of an ecological ring surrounding the city as it was facing urban sprawl because of the lack of natural barriers confining the city. 
Urban ecosystems and the Sustainable Development Goals - Maes et al. (2018)

Mainstreaming environmental considerations in local, national and global urban policymaking also implies transforming how nature is viewed in society from an unlimited, exploitable resource towards a fundamental part of our society on which our economy is built upon (Mace, 2014). One way to reconsider a nation's value and wealth is by integrating ecosystem and biodiversity values into (inter)national, regional and local accounting as called for by the SDGs. Environmental accounting provides an opportunity to understand the economic benefits of green infrastructure to our society (Gregory McPherson, 1992; Vandermeulen et al., 2011) and is included in the UK's 25 Year Environment Plan as a tool for making key choices and long term decisions (Defra, 2018). Environmental data and statistics are the basis for developing environmental accounts, while environmental accounts are used to create a set of environmental indicators (Figure 4). This process of organising information, also called the 'information pyramid', enables decision-makers to understand the meaning of data and statistics and make evidence-based decisions, connecting science with policy (Hammond et al., 1995).

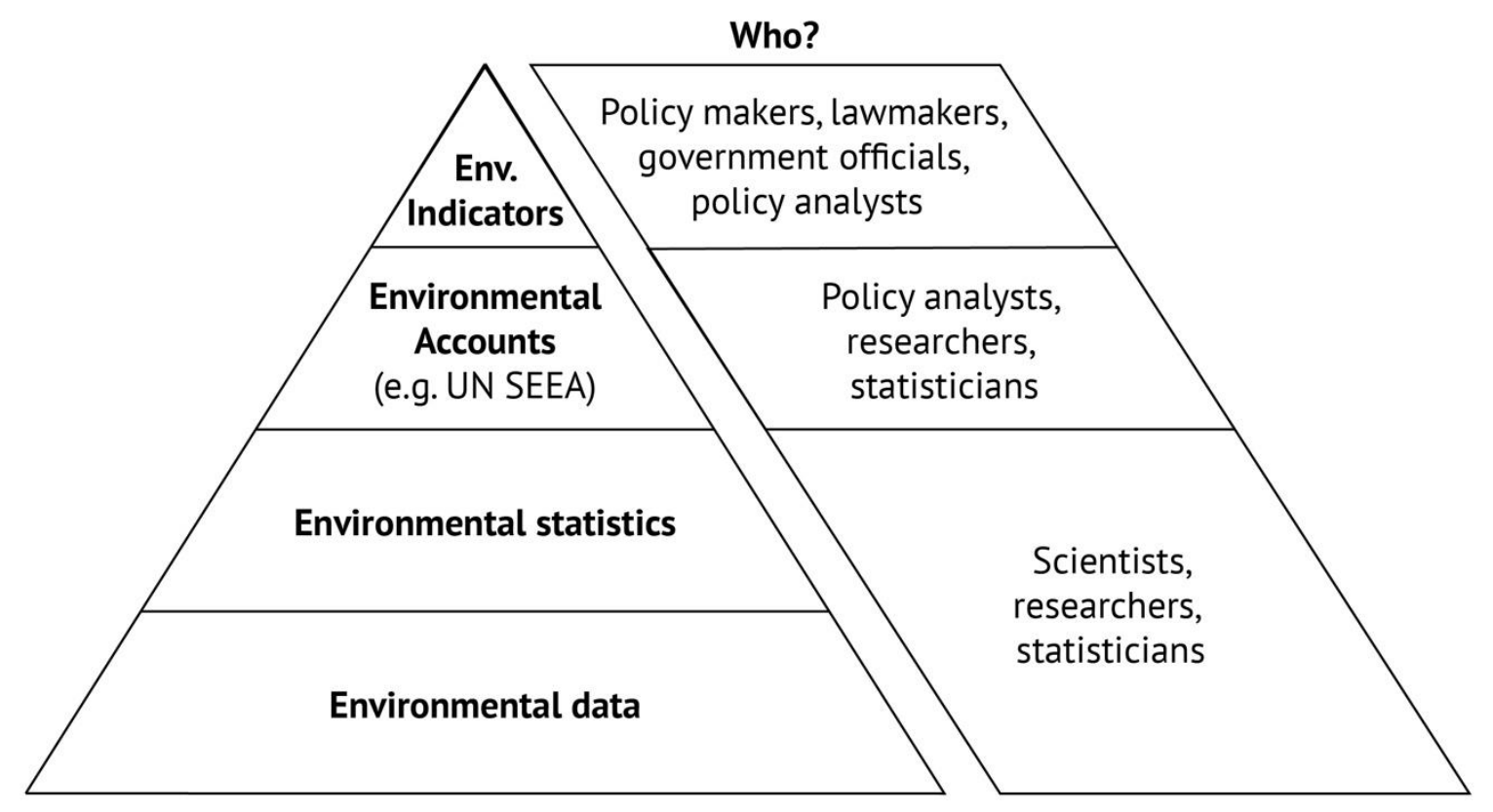

Figure 4. The 'information' pyramid shows how information can be organised. Environmental data and statistics are the basis for developing environmental accounts and indicators, connecting science with policy (Hammond et al., 1995).

The United Nations Statistical Commission adopted a central framework for environmentaleconomic accounting (UN, 2014) and other international classifications of ecosystem services have been published (Haines-Young and Potschin, 2013). Accounting for natural capital was expected to figure widely in the UN SDGs (ONS, 2015), and is represented in the UN SDGs 
Urban ecosystems and the Sustainable Development Goals - Maes et al. (2018)

through targets 12.6, 15.9 and 17.19. Realising sustainable economic growth requires decision makers to view the environment as a basis of growth. Accounting for natural capital is therefore an important part of determining the 'true' value of the economy and the wider society. Given that urban ecosystems are interlinked with many SDGs and targets (through both synergies or trade-offs), a qualitative analysis, as done here, can help ensure that actions to invest in, conserve and enhance urban ecosystems is in accordance with governance objectives on all levels.

\section{RECOMMENDATIONS}

Breaking down silos in academic institutions and decision-making bodies, and transforming the process to address societal challenges as discussed here, can only be done if human society changes. Rifkin (2010) discussed the emphatic transformation of humans in the $20^{\text {th }}$ and $21^{\text {st }}$ century, transforming from a small-range, community consciousness towards a global consciousness because of societal changes such as globalisation and the digital revolution. As people's consciousness expands beyond the community to which they are exposed on a day-to-day basis, so does their understanding that everything and everyone is interconnected. People are the driving force of change. Academic institutions can expand our knowledge of the interconnectedness between the SDGs and its targets, decision makers can restructure institutional cooperation, decision-making processes and adapt policy, but all actors need to drive this transformation. One way to facilitate this movement is by creating forums that bring together all actors. Scientists and decision makers cannot develop sustainable solutions without including all actors in society such as NGOs, volunteers and citizen groups. By including all actors in decision processes, a strategy can be developed to balance out the synergies and trade-offs between urban ecosystems and other important development goals. We translate the challenges we identified in this paper in two steps:

1. Urban research needs to be integrated, reframed and refocused. By addressing academic silo-thinking and making interdisciplinary work standard practise, published evidence will better address the challenge of interlinkages between themes affecting urban ecosystems (i.e. social, environmental, economic and governance challenges).

2. Decision-making needs to account for the published evidence generated from interdisciplinary research. Access and integration of the right information at the right time is important to support policies and decision-making. This can be done, for example, by including the value of urban ecosystems into urban accounts and 
Urban ecosystems and the Sustainable Development Goals - Maes et al. (2018)

indicators. A framework that places data and information into the centre of the policy

process, also referred to as the Policy Cycle, could facilitate this process (EEA, 2011).

Our paper is framed within a broader discussion on the role of research and decision-making in urban nature conservation by showing that various SDGs are linked to urban ecosystems. The abovementioned steps are suggested to address the challenge of dealing with evidence of interlinkages. Through these steps, researchers and policy-makers are encouraged to contribute to the future management of urban ecosystems and the consequences this might have for other challenges in society.

\section{ACKNOWLEDGEMENTS}

This research is supported by funding of the London Natural Environment Research Council Doctoral Training Programme (NE/L002485/1).

\section{REFERENCES}

Akbari, H., Kurn, D.M., Bretz, S.E., Hanford, J.W., 1997. Peak power and cooling energy savings of shade trees. Energy Build. 25, 139-148.

Alix-Garcia, J.M., Sims, K.R.E., Yañez-Pagans, P., 2015. Only One Tree from Each Seed? Environmental Effectiveness and Poverty Alleviation in Mexico's Payments for Ecosystem Services Program. Am. Econ. J. Econ. Policy 7, 1-40.

Bowen, K.J., Lynch, Y., 2017. The public health benefits of green infrastructure: the potential of economic framing for enhanced decision-making. Curr. Opin. Environ. Sustain.

CBD, 2010. Global Biodiversity Outlook 3. Montréal.

CBO, 2012. Cities and Biodiversity Outlook. Montreal.

Coombes, E., Jones, A.P., Hillsdon, M., 2010. The relationship of physical activity and overweight to objectively measured green space accessibility and use - ScienceDirect. Soc. Sci. Med. 70, 816-822.

Coutts, C., Hahn, M., 2015. Green Infrastructure, Ecosystem Services, and Human Health. Int. J. Environ. Res. Public Health 12, 9768-9798.

Cox, D.T.C., Shanahan, D.F., Hudson, H.L., Fuller, R., Anderson, K., Hancock, S., Gaston, K., 2017a. Doses of Nearby Nature Simultaneously Associated with Multiple Health Benefits. Int. J. Environ. Res. Public Health 14, 172. 
Urban ecosystems and the Sustainable Development Goals - Maes et al. (2018)

Cox, D.T.C., Shanahan, D.F., Hudson, H.L., Plummer, K.E., Siriwardena, G.M., Fuller, R.A., Anderson, K., Hancock, S., Gaston, K.J., 2017b. Doses of Neighborhood Nature: The Benefits for Mental Health of Living with Nature. Bioscience 67, 147-155.

Defra, 2018. A Green Future: Our 25 Year Plan to Improve the Environment. London.

Duarte Tagles, H., Idrovo, A.J., 2012. Biodiversity and Mental Health. In: Akeem Lameed, G. (Ed.), Biodiversity Enrichment in a Diverse World. INTECH Open Access Publisher, p. 22.

Duraiappah, A.K., 1998. Poverty and environmental degradation: A review and analysis of the nexus. World Dev. 26, 2169-2179.

EEA, 2011. Europe's environment: An Assessment of Assessments. Copenhagen.

Elo, S., Kyngäs, H., 2008. The qualitative content analysis process. J. Adv. Nurs. 62, 107115.

Farinha-Marques, P., Lameiras, J.M., Fernandes, C., Silva, S., Guilherme, F., 2011. Urban biodiversity: a review of current concepts and contributions to multidisciplinary approaches. Innov. Eur. J. Soc. Sci. Res. 24, 247-271.

Fengxiang, E.W., Han, X., Su, Y., Monts, D.L., Plodinec, M.J., Banin, A., Glover, ·, Triplett, E., 2003. Assessment of global industrial-age anthropogenic arsenic contamination. Naturwissenschaften 90, 395-401.

Fezzi, C., Harwood, A.R., Lovett, A.A., Bateman, I.J., 2015. The environmental impact of climate change adaptation on land use and water quality. Nat. Clim. Chang. 5, 255-260.

Fischer, J., Lindenmayer, D.B., 2007. Landscape Modification and Habitat Fragmentation: A Synthesis. Glob. Ecol. Biogeogr. 16, 265-280.

Forman, R.T.T., 2014. Urban Ecology: Science of Cities. Cambridge University Press, New York.

Francis, R.A., Chadwick, M.A., 2013. Urban Ecosystems: Understanding the Human Environment, 1st ed. Oxon.

Franco, L.S., Shanahan, D.F., Fuller, R.A., 2017. A Review of the Benefits of Nature Experiences: More Than Meets the Eye. Int. J. Environ. Res. Public Health 14, 864.

Gaston, K.J., 2010. Urban Ecology, 1st ed. Cambridge University Press, New York. 
Urban ecosystems and the Sustainable Development Goals - Maes et al. (2018)

Gauderman, W.J., Urman, R., Avol, E., Berhane, K., McConnell, R., Rappaport, E., Chang, R., Lurmann, F., Gilliland, F., 2015. Association of Improved Air Quality with Lung Development in Children. N. Engl. J. Med. 372, 905-913.

Gregory McPherson, E., 1992. Accounting for benefits and costs of urban greenspace.

Landsc. Urban Plan. 22, 41-51.

Haines-Young, R., Potschin, M., 2013. Common International Classification of Ecosystem Services (CICES): Consultation of Version 4, August-December 2012. Nottingham. Hammond, A., Adriaanse, A., Rodenburg, E., Bryant, D., Woodward, R., Courrier, K., Director, P., Belford, B., Manager, M., Billings, H., Manager, P., Fields, S., 1995. Environmental Indicators: A Systematic Approach to Measuring and Reporting on Environmental Policy Performance in the Context of Sustainable Development. Washington DC.

Hartig, T., Mitchell, R., de Vries, S., Frumkin, H., 2014. Nature and Health. Annu. Rev. Public Health 35, 207-228.

Harwood, T.G., Garry, T., 2003. An overview of content analysis. Mark. Rev. 3, 479-498.

Hermansen, T.D., Minchinton, T.E., Ayre, D.J., 2017. Habitat fragmentation leads to reduced pollinator visitation, fruit production and recruitment in urban mangrove forests. Oecologia 185, 221-231.

Hernandez, R.R., Easter, S.B., Murphy-Mariscal, M.L., Maestre, F.T., Tavassoli, M., Allen, E.B., Barrows, C.W., Belnap, J., Ochoa-Hueso, R., Ravi, S., Allen, M.F., 2014. Environmental impacts of utility-scale solar energy. Renew. Sustain. Energy Rev. 29, 766-779.

Hung, K.-L.J., Ascher, J.S., Holway, D.A., 2017. Urbanization-induced habitat fragmentation erodes multiple components of temporal diversity in a Southern California native bee assemblage. PLoS One 12, e0184136.

ICSU, 2017. A Guide to SDG Interactions: From Science to Implementation. Paris.

Kardan, O., Gozdyra, P., Misic, B., Moola, F., Palmer, L.J., Paus, T., Berman, M.G., 2015.

Neighborhood greenspace and health in a large urban center. Sci. Rep. 5, 11610.

Landrigan, P.J., Fuller, R., R Acosta, N.J., Adeyi, O., Arnold, R., Basu, N., Bibi Baldé, A., Bertollini, R., Bose-O, S., Ivey Boufford, J., Breysse, P.N., Chiles, T., Mahidol, C., 
Urban ecosystems and the Sustainable Development Goals - Maes et al. (2018)

Coll-Seck, A.M., Cropper, M.L., Fobil, J., Fuster, V., Greenstone, M., Haines, A., Hanrahan, D., Hunter, D., Khare, M., Krupnick, A., Lanphear, B., Lohani, B., Martin, K., Mathiasen, K. V, McTeer, M.A., L Murray, C.J., Ndahimananjara, J.D., Perera, F., Potočnik, J., Preker, A.S., Ramesh, J., Rockström, J., Salinas, C., Samson, L.D., Sandilya, K., Sly, P.D., Smith, K.R., Steiner, A., Stewart, R.B., Suk, W.A., P van Schayck, O.C., Yadama, G.N., Yumkella, K., Zhong, M., 2017. The Lancet Commission on pollution and health. Lancet 51 .

Le Blanc, D., 2015. Towards integration at last? The sustainable development goals as a network of targets. Sustain. Dev. 23, 176-187.

Mace, G., 2014. Whose conservation? Changes in the perception and goals of nature conservation require a solid scientific basis. Science (80-. ). 345, 1558-1560.

MacKerron, G., Mourato, S., 2013. Happiness is greater in natural environments. Glob. Environ. Chang. 23, 992-1000.

Maes, J., Jacobs, S., 2017. Nature-Based Solutions for Europe's Sustainable Development. Conserv. Lett. 10, 121-124.

McMorris, O., Villeneuve, P.J., Su, J., Jerrett, M., 2015. Urban greenness and physical activity in a national survey of Canadians. Environ. Res. 137, 94-100.

Nilsson, M., Griggs, D., Visbeck, M., 2016. Map the interactions between Sustainable Development Goals. Nature 534, 320-322.

Nowak, D.J., Hirabayashi, S., Bodine, A., Greenfield, E., Nowak, D.J.;, 2014. Tree and forest effects on air quality and human health in the United States. Environ. Pollut. 119-129.

Nyberg, F., Gustavsson, P., Järup, L., Bellander, T., Berglind, N., Jakobsson, R., Pershagen, G., 2000. Urban Air Pollution and Lung Cancer in Stockholm. Epidemiology 11, 487495.

ONS, 2015. UK Natural Capital, Natural Capital Accounting 2020 Roadmap: Interim Review and Forward Look. London.

Pauleit, S., Ennos, R., Golding, Y., 2005. Modeling the environmental impacts of urban land use and land cover change_a study in Merseyside, UK. Landsc. Urban Plan. 71, 295310.

Raymond, C.M., Frantzeskaki, N., Kabisch, N., Berry, P., Breil, M., Razvan Nita, M., 
Urban ecosystems and the Sustainable Development Goals - Maes et al. (2018)

Geneletti, D., Calfapietra, C., 2017. A framework for assessing and implementing the co-benefits of nature-based solutions in urban areas. Environ. Sci. Policy 77, 15-24.

Richards, D.R., Passy, P., Oh, R.R.Y., 2017. Impacts of population density and wealth on the quantity and structure of urban green space in tropical Southeast Asia. Landsc. Urban Plan. 157, 553-560.

Richardson, E.A., Pearce, J., Mitchell, R., Kingham, S., 2013. Role of physical activity in the relationship between urban green space and health. Public Health 127, 318-324.

Rifkin, J., 2010. The Empathic Civilization: The race to a global consciousness in a world in crisis. Jeremy P. Tarcher Inc.

Roe, J., Thompson, C., Aspinall, P., Brewer, M., Duff, E., Miller, D., Mitchell, R., Clow, A., 2013. Green Space and Stress: Evidence from Cortisol Measures in Deprived Urban Communities. Int. J. Environ. Res. Public Health 10, 4086-4103.

Scharlemann, J.P.W., Mant, R.C., Balfour, N., Brown, C., Burgess, N.D., Guth, M., Ingram, D.J., Lane, R., Martin, J., Wicander, S., Kapos, V., 2016. Global Goals Mapping: The Environment-human Landscape A contribution towards the Natural Environment Research Council, The Rockefeller Foundation and Economic and Social Research Council initiative, Towards a Sustainable Earth: Environment-human System. Brighton.

Shafik, N., 1994. Economic development and environmental quality: An econometric analysis. Oxf. Econ. Pap. 46, 757-773.

Shanahan, D.F., Bush, R., Gaston, K.J., Lin, B.B., Dean, J., Barber, E., Fuller, R.A., 2016. Health Benefits from Nature Experiences Depend on Dose. Sci. Rep. 6, 28551.

Sokka, L., Sinkko, T., Holma, A., Manninen, K., Pasanen, K., Rantala, M., Leskinen, P., 2016. Environmental impacts of the national renewable energy targets - A case study from Finland. Renew. Sustain. Energy Rev. 59, 1599-1610.

Stern, D.I., Common, M.S., Barbier, E.B., 1996. Economic growth and environmental degradation: The environmental Kuznets curve and sustainable development. World Dev. 24, 1151-1160.

Tallis, M., Taylor, G., Sinnett, D., Freer-Smith, P., 2011. Estimating the removal of atmospheric particulate pollution by the urban tree canopy of London, under current and future environments. Landsc. Urban Plan. 103, 129-138. 
Urban ecosystems and the Sustainable Development Goals - Maes et al. (2018)

Thompson, C.W., Roe, J., Aspinall, P., Mitchell, R., Clow, A., Miller, D., 2012. More green space is linked to less stress in deprived communities: Evidence from salivary cortisol patterns. Landsc. Urban Plan. 105, 221-229.

UN, 2014. System of Environmental-Economic Accounting 2012: Experimental Ecosystem Accounting. New York.

UN, 2015a. World Urbanization Prospects - Revision 2014. New York.

UN, 2015b. The Millennium Development Goals Report 2015. New York.

UN, 2015c. Resolution adopted by the General Assembly on 25 September 2015 A/RES/70/1 on transforming our world: the 2030 Agenda for Sustainable Development. New York.

UN HABITAT, 2016. World Cities Report 2016. Nairobi.

UNEP, 2012. Advancing Justice, Governance and Law for Environmental Sustainability. Nairobi.

UNEP, 2016. Global Gender and Environment Outlook. Nairobi.

Vandermeulen, V.., Verspecht, A.., Vermeire, B.., Van Huylenbroeck, G.., Gellynck, X., 2011. The use of economic valuation to create public support for green infrastructure investments in urban areas. Landsc. Urban Plan. 103, 198-206.

Vaz Monteiro, M., Doick, K.J., Handley, P., Peace, A., 2016. The impact of greenspace size on the extent of local nocturnal air temperature cooling in London. Urban For. Urban Green. 16, 160-169.

Waage, J., Yap, C., Bell, S., Levy, C., Mace, G., Pegram, T., Unterhalter, E., Dasandi, N., Hudson, D., Kock, R., Mayhew, S., Marx, C., Poole, N., 2015. Governing the UN Sustainable Development Goals: interactions, infrastructures, and institutions. Lancet Glob. Heal. 3, 251-252.

Wolch, J.R., Byrne, J., Newell, J.P., 2014. Urban green space, public health, and environmental justice: The challenge of making cities 'just green enough.' Landsc. Urban Plan. 125, 234-244.

Yang, J., Yu, Q., Gong, P., 2008. Quantifying air pollution removal by green roofs in Chicago. Atmos. Environ. 42, 7266-7273.

Zhao, Y., Christensen, T.H., Lu, W., Wu, H., Wang, H., 2011. Environmental impact 
Urban ecosystems and the Sustainable Development Goals - Maes et al. (2018)

assessment of solid waste management in Beijing City, China. Waste Manag. 31, 793799. 
Urban ecosystems and the Sustainable Development Goals - Maes et al. (2018)

\section{ELECTRONIC SUPPLEMENTARY MATERIAL}

2 Full results for answering the methods are available in full in the attached pdf document and

3 can be found in the online version of this article. 